Сочиолошки преглед, год. XLIV (2010), бр. 1, стр. 139-149.

OCBPT

Petar Opalić

Milana Ljubičić

Faculty of Philosophy

University of Belgrade
Scientific Review

Received:

5. 03. 2010.

\title{
INVESTIGATIVE STUDIES ON CONSEQUENCES OF WAR INFLICTED TRAUMA IN SERBIA (Books review)
}

\section{Introduction}

Bearing in mind relatively insignificant amount of reports and scientific studies on mass trauma consequences in the region of Balkans, especially Serbia, in the Western publications, we have come to a conclusion that introduction to books or monographs dealing with the problem, would, not only fill the gaps, but give an opportunity to those practically engaged in the subject (psychiatric and psychotherapeutic experts, medical and so-called Disaster medicine specialists), as well as experts in social science domain, firstly sociologists, psychologists, ethnologists and historians who could use it to complete the familiarity on this subject matter. We shall present several well noted works by Belgrade authors who deal with the problem of influence of general social change in Former Yugoslavia on metal health of population. The authors of those studies are distinguished psychiatrists, psychologists, psychotherapists and physicians, who have conducted bibliographical material research as well as reporting on basic therapies or preventive activities and mental health protection programmes for jeopardised population, firstly refugees.

The selection of studies was based on several criteria. One of the most important is the one underlining absence of subjective or political propositions, scientific approach as the key principle is undoubtedly stresses out. The second concerns the time frame that can, conditionally, be divided in three parts; the first is marked with immediate war jeopardy, the second, which includes analyses of general conesquences, covers the after conflict period, and the third follows the long-term conesquences 10 years after the war.

Besides, we believe that those studies should be presented to expert public eye for more reasons. Firstly for the sample selection, than the research instruments at use and the manner of data analyses, for all of which those studies remain scientifically indubitable and verified testimonies on events in Former Yugoslavia. Furthermore, the magnitude and particularity of presented research material in phenomenological and social sense with due respect for basic scientific principles without which those studies would, more or less, illustrate a personal account, chronicles 
Petar Opalić, Milana Ljubičić, Ivestigative Studies on Consequences of War Inflicted Trauma

or notes, possibly, at later date, subjected to similar interpretations or falsifications at will.

Heuristic value of those studies is also indubitable. All of those at the same time are experiences testimonies on introduction of specific therapies, prevention and similar measures on eliminating subjective and interpersonal consequences of physically and mentally traumatised and handicapped individuals and their families in the region of Central and Western Balkans.

Besides, all of the studies are theoretically well based (mostly neutral) and free from doctrinarism and therefore dominated by multidisciplinary approach in research and theoretical sense.

The use of broad and contemporary literature is a special quality that made us believe that by, itself or compared to similar studies, can provide a useful source for comparative research in this field.

\section{Demonstration of methodological design and results of certain individual studies}

a) The book War Psycho-trauma and Family written by Doc Dr Aleksandar Jovanović from the Institute for Psychiatry of Clinical Centre of Serbia is a study of 160 victims of war in Bosnia and Herzegovina, 70 of whom have been direct victims of torture in Croatian and Muslim prisoner of war camps. The author firstly provides an insight and clarification of diagnostic uncertainties related to PTSD, to proceed to the problems of general prevention and trauma suffered by the families and concludes that the greatest stress is caused by physical injury with mutilation; followed by trauma of painful rehabilitation.

The study of 80 subjects for PTSD symptoms (35 victims of torture, Serbs, detained in Croatian and Bosniak camps of war and 45 patients of Institute for Psychiatry of Clinical Centre of Serbia) and 80 control group subjects with no psychiatric diagnoses (35 victims of torture in the aforementioned camps and 45 patients of Institute for orthopaedic prosthetics in Belgrade). The sample was balanced in main socio-demographic characteristics: the gender, age and marital status. During the research the author used an impressive set of 18 research instruments: Psychiatric and Specially Structured Interview, Scale of Global Function GAF, Hooper's Test of Visual Orientation, Scale of Events Effect, Short Scale of Psychiatric Assessment and Self-assessment, Anxiety Self-assessment Scale, Scechan's and Scale of Hopelessness, Family Events Questioner, Family Hardness Index - FHI, Index of Family Cohesion in Overcoming Difficulties, Social Support Index, Scale of Tactics in Overcoming Conflicts and a Scale of Clinical Assessment of Marital and Family Functionality within Circumflex Model. The author remarked, based on research results, that significantly greater number of subjects suffering from stress induced psychiatric sequelae were of urban origin or with low income (below $100 \mathrm{DM}$ ). Before the research psychiatric disorders were signify- 
Сочиолошки преглед, год. XLIV (2010), бр. 1, стр. 139-149.

cantly present in the control group, a fact that only supports influence of heritability in reactive psychic disorders.

It is interesting that the experimental group included more subjects who have experienced deportation and torture mainly because of belonging to Christian Orthodox Faith and Serb nation which underlines the significance of socially inflicted stress factors of psychiatric disorders. Author also noted significant correlation between reactive psychological disorders and week family cohesion that was calculated by Family Cohesion Test. Furthermore, families with a member suffering from PTSD were characterised by poorer psycho-social adaptability.

He concludes, referring to UN Convention from 1985, with a list of 41 physical, psychological and combined torture, characteristic by inhumane sadism and perfidy, which prisoners of war - Serbs - have been exposed to, to say that people have been tortured mostly for being of different ethnicity.

b) Authors of the book Psycho-social Study of Amputees - Victims of War in Former SFR Yugoslavia During 1991 to 1995, Jovanović A, Pejović M, Vranić K, Radotic $\mathrm{M}$, have tried to answer the questions in regard to several trauma types; primary (caused by immediate stress experience), secondary (suffered by family members) and third (suffered by wider social surrounding and descendants of the victims). The emphasis was placed on investigation of complex process of rehabilitation and pharmacological, physical, counselling, professional and social treatment of severely injured subjects. Authors have pointed out the main causes of psychological reaction to amputation and subjective fazes of response to loss of body (acute faze with shock, sub acute faze comprising PTSD elements, late faze varying in psychological composure and discomposure) and the specifics of biomedical rehabilitation in pre- and post- surgery, prosthetic and post-hospital period of rehabilitation. The research engaged 50 war amputees who demonstrated no signs of psychiatric disorders (experimental group) and 203 amputees without psychological change (control group) from Serbia and Republic of Srpska (BiH). During the research set of 9 research instruments was used: two Anamnesis Interviews, Scale of Global Function, Scale of Hopelessness, Social Support Index, Index of Family and Friends Support, Profile Index of Emotion by Ploechick, Index of Family Cohesion in Overcoming Difficulties, Family Hardness Index and Scale of Events Effect. After employment of complex statistical procedures (analyses of variance and similar), the results revealed that patients who were in preprosthetic faze of rehabilitation displayed the most extensive signs of physiological change (mainly reactive disorders, depression and PTSD). The exact same subjects have gained lower score on Social Support Scale since they were more dependant on third party care, with, on the other hand, statistically significant shortcomings in regard to professional rehabilitation. The results of Plouchik's Test revealed that experimental group subjects are more often under burden of symptoms, depression, aggressiveness and anxiety.

Furthermore, depressiveness was indicated to be the innermost prognostic feature (also visible from the correlation with the results of GAF) since it can lead 
Petar Opalić, Milana Ljubičić, Ivestigative Studies on Consequences of War Inflicted Trauma

to, as authors have stated in chapter "Therapy of war psycho-trauma", delayed and permanent weakening of rehabilitation motivation or addiction to psycho-active substances and further development of psychosomatic disorders.

Authors, besides, point out the therapy techniques used in treatment of psychological conditions of the amputees (individual, cognitive, behavioural and group psychotherapy as well as family therapy). They also emphasised the principle approach guiding them which was to barrier from the moral and the political attitudes regarding the war with the aim to easier overcome two potentially conflicting realities, the one of war and the one of peace.

c) The study Psychophysical Trauma and Acute Stress Disorder, by Dr Blagoje Kuljić, psychiatrist of Mental Health Institute in Belgrade, is a retrospective by its nature aiming to reveal the risk factors contributing to development of the Acute Stress Disorder (ASP) in trauma sufferers (the wounded), as well as its correlations. The sample was homologous by gender, age and trauma phenolmenology.

The study is divided in two parts. The first, theoretical part, draws attention to the theories and the consequences of stress by explaining neuro-biological, psychoanalytical, psychological and theoretical concepts on ASP development risk factors and its symptoms, and the possibilities of distinction from PTSD. In the second part author acquaints us with the results of research into ASP risk factors conducted personally in Belgrade. To clarify, he has set a basic hypothesis that the emergence of ASP is Conditioned by the trauma nature and its physical conesquences, (including, firstly, trauma severity and neuro-endocrine changes) as well as the personality of the traumatised subject.

B. Kuljić used a number of instruments during his research: to assess the injury character Injury Severity Score and Abbreviated Injury Scale, whilst the trauma perception and its consequences were assessed by Brief Disaster Questionnaire, Impact of Event Scale, Hamilton Anxiety Rating Scale and Spielberg State Anxiety Inventory. Pre-injury personality assessment was based on the Eysenck Personality Questionnaire and Spielberg Trait Anxiety Inventory. The study gained special quality by prospective insight into post-injury neuro-endocrine status of T3, $\mathrm{T} 4$, TSH, cortisone, testosterone, prolactine, insulin and growth hormones which have been monitored for the period of seven days. Study involved 83 subjects wounded during Kosovo conflict in 1999. Those subjects have been hospitalised and treated at Medical Military Academy in Belgrade. Selection criteria included compulsory loss of conciseness immediately after wounding and positive personal history to various psychiatric illnesses. Experimental group involved 30 wounded subjects diagnosed with ASP and a control group 53 wounded who did not show symptoms of ASP.

Author investigated influence of several factors that he considered to be risk factors. In the first instance he considered the character of injury including the mode of infliction which was established to be of a predicative significance for ASP emergence. Therefore, the injuries sustained following an explosion and so- 
Сочиолошки преглед, год. XLIV (2010), бр. 1, стр. 139-149.

called blast injuries have been noted to have a positive correlation with ASP emergence. The second important risk factor is personal perception of the trauma and its consequences. It was established that the sense of immediate life threatening danger and the attitude that the injury will bear extremely negative personal and social consequences is a significant factor in ASP development. It is interesting to note that objective severity of the injury does not necessary correlate with the subjective perception. The following factor featured is pre-injury personality characteristics. It was established that narcissism and anxiety are more common in the experimental than the control group. And finally, the last risk factor that the author singled out, is neuro-endocrine status after injury which was monitored for seven days after the hospitalisation. According to the laboratory test the author noted that neuro-endocrine status is determined by the injury severity and not by possible psychopathological causes. The author than proceeded to conclude that the research results into presumed factors that might have caused development of ASP are not convincing beyond doubt apart from those variables concerning psychological perception of trauma.

d) Stresses of War is a study conducted by a large group of authors, eminent professional Prof. Dr Kaličanin P. and others, mainly employed at Mental Health Institute in Belgrade. It originated during the war conflict on the territory of Former SFR Yugoslavia. The study contains number of papers on research and theories on psychopathological manifestations within the most vulnerable group of population. It relates to children, youth, refugees, soldiers on the front lines, prisoners of war and their reactions to stressful situations.

The study is quite significant since it contains some of the earliest information on adoption of therapeutic and preventive measures aiming to protect mental health of population in conditions of exposure to mass trauma.

The main research methods used by the authors were semi-structured interviews, documented material - history of illness, one year follow-up, semi-standardised psychiatric-psychological interviews, observation of immediate behaviour and reactions and methods of free verbal expressions of the subjects. Conditionally, the paper can be divided into five parts. In the first part the authors give introduction to basic concepts and programs of preventive action regarding the protection of mental health of jeopardised population. The second part dwells upon the research into psychological consequences that war inflicts on refugee children and families in general with retrospect view on consequences that WWII left on Jewish children. Third part studies severe psychological consequences that, without doubt, pertain to the war and the trauma it triggers. In the next part authors, on example of Vukovar, present an almost sociometric analyses of shelter and "survival communities" residents who are both mentally in good and poor health. And the final part addressed the problem of ethics in psychiatry and its malicious use in politics.

In the first part authors introduce us to the metal health protection prevention programs in the conditions of mass trauma - war. The significance of this paper is based on the fact that such programs have not even had the roots before the war 
Petar Opalić, Milana Ljubičić, Ivestigative Studies on Consequences of War Inflicted Trauma

conflict. Therefore, it is of utmost importance to stress out that professionals in this field have instantly after the conflict in Former Yugoslavia broke out, created a program with the aim of: prevention of psychosocial consequences of mass trauma affecting those considered to be at the most risk; children, juveniles, wounded and their families, refugees living in shared accommodation and individuals suffering from PTSD. The program included activities on secondary prevention, rehabilitation of ill, as well as planning protection and work with the most vulnerable to mental disorders including education of experts and amateurs alike

The second part deals with children and juveniles and their reaction on mass trauma conditions. Since the juvenile population possesses lower stress defence potential it had been established that they are particularly vulnerable population. The most common emotional response to stress ranged from extreme anxiety, depression, fear of separation and various behavioural disorders. Besides, it was established that children and young refugees accommodated in shared housing are at higher risk. Moreover, the psychosocial reactions of young refugees, aged between 3 and 15.9, who fled the areas of Former Yugoslavia affected by the war conflict between Jun and October 1991, have been monitored. The research involved 326 children accommodated within the families and 256 in Pančevo in «Čardak» refugee shared accommodation. The control group was formed by 182 children from the local community. Both groups were equivalent by gender, age and socio-economic status. The results have confirmed that mental health of children-refugees is at most risk: $34 \%$ of those children have manifested symptoms that backed up the diagnoses as opposed to $11.6 \%$ of locally living children. The most common diagnoses were: depressive and anxious reactions and post trauma stress reactions. Besides, it is characteristic that more children living in shared accommodation have been diagnosed as opposed to children living within families.

Authors acquainted us with potential puberty crises of children refugees: crises of identity and ethical values that consequently bear risk of antisocial behaviour, anxious and depressive reactions and somatization. In addition, authors have, referring to retrospective studies on psychosocial consequences that trauma caused to Jewish children during the WWII, predicted the possibility of long term followup studies of children and young refugees with conclusion that: “....the time distance, ethical, religious and cultural barrier can not weaken mutual cross of overall human pain" $(1994,49)$. Finally, in the sprit of true cross-cultural study, authors introduced us to the research of psychosocial consequences of war on Former "Yugoslavians", emigrants in Sweden. The research involved 250 subjects, patients of the first and the second generation of emigrants from Former Yugoslavia who expressed signs of psychological disorders. Based on one year follow-up the authors established that war conflict in homeland has deeply affected development of psychological disorders in emigrants in Sweden, with exemption of juveniles and those married to foreign partners, since significant emotional connection to homeland is missing in both cases. 
Сочиолошки преглед, год. XLIV (2010), бр. 1, стр. 139-149.

The objective of the next part is to introduce severe mental disorders ethnology that are directly connected to war and the participation in the conflict. The research involved 384 subjects who have been treated in 21 psychiatric institutions in Serbia between $1^{\text {st }}$ of June 1991 and $1^{\text {st }}$ of January 1993. The basic selection criterion was the existence of severe psychic disorder caused or worsened by war events that required hospital treatment. The results gained gave an opportunity to authors to assess the risks for triggering certain types of reactive disorders depending on the nature of stress. It was established that refugees suffered greatest stress over separation from the kin and the loss of property, the soldiers particularly emphasised the stress caused by experience of direct combat. Authors paid particular attention to investigation of psychosocial response from prisoners of war. The interviews were conducted with 141 subjects, Serbs, of homogenous gender, age and socio-economic characteristics, who have been released from detention facilities. In addition to finding physical signs of torture, authors have noticed unusual and strong psychological resilience in relation to intensity and duration of stressful events.

Moreover, the accent is placed on widely spread intoxication mania amongst the soldiers and Serb refugees from Bosnia and Croatia. Based on the research of large sample conducted in shared refugee accommodation in Serbia and 35 wounded soldiers in rehab faze, authors established that alcoholism in such extreme living conditions had stress alleviation role but facilitates development of pseudo toxi-mania phenomena.

The authors also distinguished between two categories of drinking amongst the soldiers: first category of inclined alcoholics which included drinking before and after the stressful events whilst in the second category were non-alcoholics who started alcohol consumption only after being in immediate life threatening danger.

The fourth part of the study deals with an almost sociometric analysis of behaviour amongst residents of war consumed Vukovar. Authors give us an insight into wide spectrum of behaviour of population who sought protection in shelters and «protection communities» and functionality of spontaneously formed communities in which all individuals performed different tasks with the main aim of providing means of living. A special accent is placed on mentally ill people. By living with healthy population in the same existential conditions they functioned surprisingly satisfactory.

The fifth, last, part of the book relates to the misuse of medical and psychiatric science and consequences of such breach of medical ethics. That is, in «Croatian Medical Magazine» psychiatric experts call upon some psychoanalytic and similar theories to explain «inhumane savage urge» of war conflicting parties however, excluding their own peoples from negative qualification. The final aim of this pseudo-scientific argument was, in authors' opinion, to satanize one nation, in this case Serb, for war purposes.

e) In his book Qualitative and Psychometric Research of Refugees and Traumatised Subjects in Belgrade, edited in Germany, psychotherapist and psychiatrist 
Petar Opalić, Milana Ljubičić, Ivestigative Studies on Consequences of War Inflicted Trauma

from Institute for Mental Health Prof. Dr Petar Opalic, deals with problem of reaction to general psychopathological trauma in the light of social constellations and its influence on emergence of psychopathology of exiled and physically traumatised persons in Belgrade. The accent is placed on qualitative and psychometric research of certain aspects of psychological life of refugees. The aim of the study was to establish which consequences the trauma of exile and forced adjustment to a new and harder life leaves on the psyche of the individuals opposed to physically traumatised.

The author, on one hand, placed accent on establishing connection between exile and physical trauma on one side and personality characteristics, extrovert and introvert, on the other. Special attention was paid to determining family cohesion and relation between socio-demographic features of refugee population of physiccally traumatised and their psychological integrity as being potential factors of risk to development of personal psychopathology. The research sample consisted of two groups: the experimental group involving 109 refugees from Bosnia and Croatia between 1991 and 1995 who were accommodated in refugee camp Krnjaca near Belgrade and the control group of 175 non-refugees (70 of whom suffered somatic trauma and were hospitalised at Orthopaedic Clinic of Clinical Centre of Serbia in Belgrade and 105 subjects who denied any trauma experience, also from Belgrade).

During the course of research, the author combined qualitative and quantitative research methods. The following instruments were used: questioner for establishing socio-demographic features of subjects, PTSD-10 scale, Short Eysenck Inventory for Research of Neuroticism and Elements of Extroversion and Introversion, Family Homogeneity Inventory, Impact of Events Scale to investigate ways of overcoming misfortunate consequences, Dreams Analyses and Machover's Test (human figure drawing). With the intention to familiarise the audience with existential aspects of refugee's lives the author offered qualitative outline of their life stories in a form of a biography giving the reader an opportunity to understand their tragedy.

The study is divided in five parts. The first part deals with exile problem in Serbia, somatic psychopathology and exile of traumatised. The second part is a study of their dreams. The third part investigates consequences of exile and somatic trauma on psychological identity of individual. In the next part Prof Dr Opalić, by the use of Mahover Test, deepens the analyses of psychological life of traumatised. The last part is dedicated to refugee's life stories.

Results of Eysenck Personality Inventory, PTSD Symptoms Assessment Scale, have shown that overall neuroticism and extroversion are significantly present with non-traumatised population, whilst symptoms of (most probably chronic) PTSD considerably burden refugees. It should be added that amongst PTSD symptoms in refugees, social isolation symptoms, opposed to inflicted symptoms (nightmares, unwilling memories), and symptoms of irritability (poor concentration, emotional bluntness, loss of interest for ordinary activities), are, statistically, more frequent. 
Сочиолошки преглед, год. XLIV (2010), бр. 1, стр. 139-149.

Those findings Opalic interpreted in the light of existential status of refugees who are potentially and factually disabled from participation in social life (unemployed, with no housing, and the last but not the least unaccepted in the new community) that demands adaptation of different living conditions. It has been noted that some socio-demographic characteristics of refugees, primarily marital status and gender, influenced adaptation abilities of an individual. Therefore, married man, opposed to women, are more often troubled with PTSD symptoms. Viewed in the light of Parsons Male - Female Role Division, those findings explicitly support the theses that women who revolve around family are more protected unlike men who, with the loss of wider social surrounding lose their social role and psychological integrity.

The second part of the study expands analyses of psychological life of refugees by qualitative analyses of various characteristics of dreams. The dreams not only point out present existential position of the dreamer, but are the treasury for recognition of psychological problems. The author, therefore, widely analysed dreams and some of their formal significance, emotional colour and types of dreams, correlation between dreams and some psychopathological conditions and differences in dreams in both sample groups. Analyses have shown that refugees opposed to non-refugees, significantly more often have dreams with negative pretext, connected to trauma and context of war. Besides, it was noted that there is a positive correlation between dreaming (excluded are traumatic dreams followed by fear) on one side and attitude towards trauma consequences on the other. The dreams of refugees have clearly testified about their existential status and psychological integrity.

By using Mahover Test (human figure drawing), the author further deepened the personality analyses. Since the drawings were less censured than verbal communication, the aim was to establish the hardly noticeable aspects of psychological condition of subjects through graphological expressions on human image drawing in the context of traumatic experience. He offered us interpretation of motion expression from the angle of psychoanalytical and existentialist approach presenting, without hesitation, inaccuracies (the drawing can express present needs or interpersonal conflicts of the subjects) and advantages of Mahover Test. Mahover Test made possible the recognition of some of diagnostic entities of the such as neurosis, depression, schizophrenia, paranoia, organic impairments and three categories that stood out in particular which are: motion deficiency, alcoholism and aggressiveness. To clarify, physical deficiencies or somatic trauma as well as experience of exile, adequately presented in graphology by vogue central body line, missing upper or lower limbs and broad body contours, are statistically significant within the group of traumatised subjects compared to non-traumatised.

Drawings of such quality represent existential expression of physical scheme disorder and act as innuendo of jeopardy to physical integrity of individual, some sort of existential bolt to particular area. It is significant that among all of the diagnostic categories motion deficiency (influence of physical trauma on 
Petar Opalić, Milana Ljubičić, Ivestigative Studies on Consequences of War Inflicted Trauma

perception of physical scheme) is a prominent one followed by aggressiveness amongst refugees. It could be interpreted, in author's opinion, either as permanent personality characteristic or gained behaviour or as motion abreaction to the internal conflict caused by adverse external conditions. By underlining the basic theoretical frame, in the final part author gives us an insight into interesting life stories of some individuals, somatically traumatised and refugees enriching results of the above quantitative analyses.

\section{Conclusion}

In conclusion our summary represents retrospective insight into studies produced in Serbia that dealt with mass trauma and the later consequences on mental health of Belgrade and Republic of Srpska residents. Choice of studies depended on several criteria: firstly time frame, variousness of present and even to the day accurate phenomenology and instruments and methods used in research purposes. On the other hand choice of studies greatly depended on high regard for scientific principles and the fact that the studies complied with basic scientific criteria in regard to sample size, data processing, existence of control group and have undergone recension prior to publishing.

All of the analysed studies focus on population assessed to be the most vulnerable to mental disorders like children, juveniles and refugees (first and last study), wounded (second and the fifth study) and prisoners of war (fourth study). Apart from the study conducted by Dr Blagoje Kuljic whose subjects were wounded non-refugees, the phenomenology of exile, war imprisonment and war inflicted injury is present in all the other research papers. Multiple trauma of exile, wounding or shockingly inhumane trauma of torture, subjects of the studies, mainly originating from Belgrade and Serb entity of Bosnia and Herzegovina, have, in some cases, shown remarkable resilience to trauma (especially prisoners of war) but also significant vulnerability to mental disorders as opposed to subjects pertaining to control groups.

The seriousness of those findings are underlined by the fact that traumatic experiences remain persistent at sensitive and sensory level and bear danger of passing on trauma to next generations due to difficulties of verbal communication by Farlan (Opalić, 2005). Moreover, it is estimated that on territory of Former Yugoslavia about $20 \%$ of refugees, whose approximate number in 1998 was one million including about 200000 of internally displaced from Kosovo and Metohija, suffer from PTSD. Particular problem of exiled population, also pinpointed by the most significant symptom of PTSD (ethology of which is for the most part social), is social isolation and low level of incorporation of refugee population into «new» society. Accommodating attitude of domicile populace and Republic of Serbia towards refugees is only declarative whilst, in actual circumstances, the attitude of both is ambivalent. Moreover, we can not look past possibility of the potential secondary impact on exiled bearing a mark as being losers, newcomers, symbo- 
Сочиолошки преглед, год. XLIV (2010), бр. 1, стр. 139-149.

lically culpable for overall poverty, national defeats and similar. Widely spread subculture of ill-fate, passive attitude to difficulties resolution and long-term symptomatic reactions to adversities (confusion, social inhibition), as accepted by the World Health Organisation, represent fertile ground for this secondary effect.

On the other hand, wounded persons are stigmatised (portraits of national failure) and socially (even in scientific sense) forgotten since it is a fact that very rarely experts research psychosocial condition of wounded.

The aim of this summary was to, amongst other, point out the ways in which professionals in Serbia analysed the problem of mass trauma and its consequences and the need of, in our opinion, longitudinal research of long term consequences. It should be remembered that the majority of population prone to mental disorders, namely refugees, wounded, prisoners of war, is marginalised and somewhat stigmatised. This paper represents our desire to divert attention to this problem and to make wider scientific and professional public aware of the magnitude and phenomenology of trauma affected populace in one part of Balkans neglected by the world public.

\section{Literature (ANALYSED STUDIES):}

Jovanović A. (1997): War Psycho-trauma and Family, Zadužbina Andrejević, Belgrade Jovanović A., Pejović M., Vranić K., Radotić M. (1997): Psychosocial Study of Amputees - Victims of War in Former Yugoslavia during 1991-1995, Association to Aid Refugees, Margo Art, Belgrade

Kaličanin P., Bukelić J., Išpanović-Radojković V., Lečić-Toševski D.(ed.) (1994): Stresses of War, Institute of Mental Health, Belgrade

Kuljić B. (2003): Psychophysical Trauma and Acute Stress Disorders, Zadužbina Andrejević, Belgrade

Opalić P. (2005): Qualitative and Psychometric Research of Refugees and Traumatised Subjects in Belgrade, Psychosozial-Verlag, Giessen 